\title{
White Light Electroluminescence by Organic-Inorganic Heterostructures with CdSe Quantum Dots as Red Light Emitters
}

\author{
Ilker Oner, ${ }^{1}$ Elias Stathatos, ${ }^{2}$ and Canan Varlikli' ${ }^{1}$ \\ ${ }^{1}$ Solar Energy Institute, Ege University, Bornova, 35100 Izmir, Turkey \\ ${ }^{2}$ Electrical Engineering Department, Technological-Educational Institute of Patras, 26334 Patras, Greece \\ Correspondence should be addressed to Elias Stathatos, estathatos@teipat.gr and Canan Varlikli, canan.varlikli@ege.edu.tr
}

Received 19 May 2011; Accepted 6 July 2011

Academic Editor: Zoran Ikonic

Copyright ( $) 2011$ Ilker Oner et al. This is an open access article distributed under the Creative Commons Attribution License, which permits unrestricted use, distribution, and reproduction in any medium, provided the original work is properly cited.

\begin{abstract}
We have developed a white organic light-emitting diode featuring a double emission layer comprising a blue light-emitting conductive polymer as a host material for Cadmium Selenide (CdSe) quantum dots as red light emitters and tris-(8hydroxyquinoline) aluminium thin layer for green light emission. The Commission Internationale de l'Eclairage coordinates of the emitting light of the device were found to be $(0.32,0.40)$ which were only slightly changed over a range of applied voltages between 5 and 10 volts. The use of CdSe nanocrystalline quantum dots (surface-stabilized with hexadecylamine/trioctylphosphine oxide ligands) in the hybrid heterostructure with poly(9,9-di-n-octylfluorenyl-2,7-diyl) conductive polymer was studied for a variety of CdSe concentrations developing the performance of the device in means of overcoming segregation problems in the blend. Besides, constituents' ratio was further examined for the exploration of possible energy transfer from polymer host material to the CdSe quantum dots as a key factor for well-balanced emission in the electroluminescent devices.
\end{abstract}

\section{Introduction}

Electroluminescence as a result of radiative recombination of electrons and holes in an inorganic semiconducting material is a well-known phenomenon for many years with a variety of applications usually in common LEDs [1]. The use of organic semiconductors either in form of conjugated polymers or small molecules is a more recent technological development of the initial idea. Since the first announcement of organic light-emitting diodes (OLEDs) [2] and polymer-based light-emitting diodes (PLEDs) [3] an extensive research has been established which led these devices to the commercialization stage $[4,5]$. The basic advantage of these devices is the easy fabrication process using a variety of small molecules [6] or conductive polymers [7] where common deposition techniques such as dip coating, spin casting, and inkjet printing are used. Furthermore, the variety of conductive organic materials and new trends in materials' modification has led the OLED technology to present high-efficiency devices with long-term stability in a variety of emitting colours and turn-on voltages [810]. However, the most attractive emitting colour in LED industry is the white colour as it may offer many benefits in lighting technology including energy saving (e.g., flashlights, architectural lighting, displays backlighting, and large area displays).

The fabrication of a white emitting LED based on organic materials (WOLED) is an attractive idea which was developed in very recent years $[11,12]$. Since then an intense research activity was performed in the improvement of colour instability and low efficiency. In general, the white colour may be obtained by mixing the three primary colours: red, green, and blue which have to be simultaneously produced. Nevertheless, in semiconductor technology the creation of quantum size particles has attained their use in many applications such as electronics and optoelectronic devices because of their strong quantum size confinement effects $[13,14]$. The inorganic nanocrystalline semiconducting quantum dots (QDs) may exhibit high photostability with narrow emission widths of which the wavelength mainly depends on their particle size $[14,15]$. This unique advantage of semiconducting QDs may succeed to the emission of a relatively monochromatic light tuning by slight deviation in particle size covering this way the whole visible range 

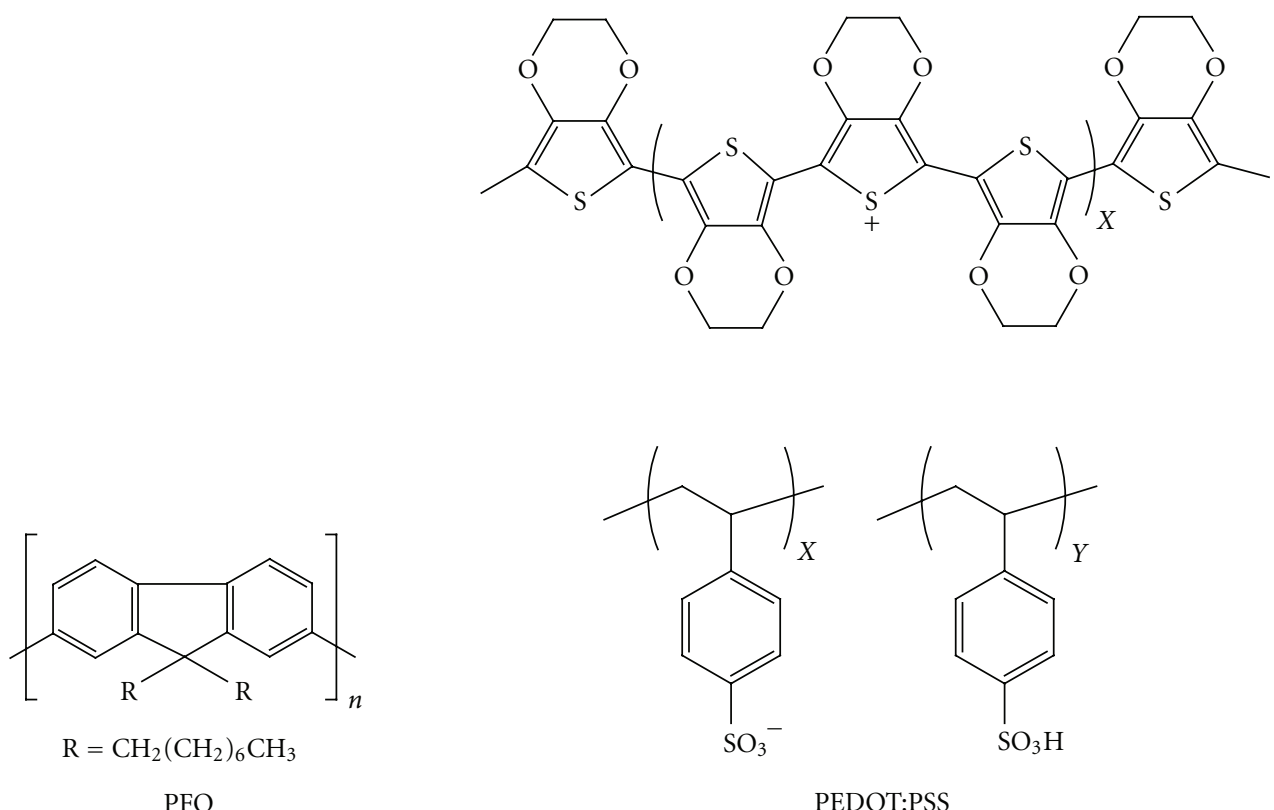

PEDOT:PSS

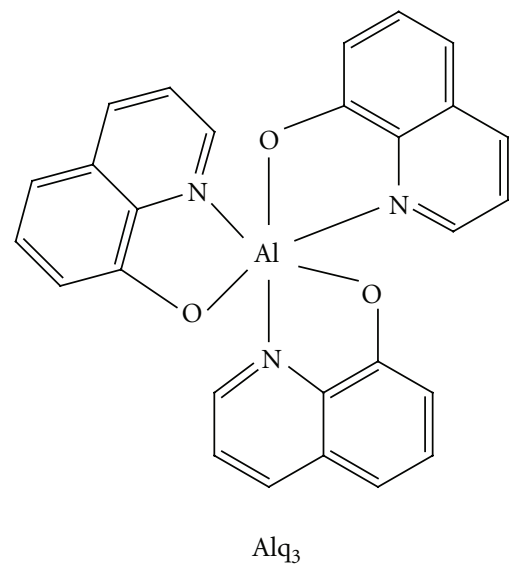

SCHeme 1: Chemical structures of the employing materials.

[16]. Much effort has been given on the combined IIVI semiconductor nanocrystals such as CdSe, CdS, ZnSe, and CdTe [17, 18]. Combination of QDs of different size and therefore emitting light may lead to the creation of white light [16]. Alternatively, white light may be produced by hybrid materials of polymers and semiconducting QDs which combine the easy processability of the polymers and unique advantage of the inorganic QDs of tuning their emitting light by slight modification of their size which nevertheless exhibit poor process application $[19,20]$. However, a limited number of studies have been reported on hybrid white light-emitting electroluminescent devices based on QDs and polymers where the emission mechanisms are rarely investigated.

Herein, we explored the use of CdSe nanocrystalline QDs (surface-stabilized with hexadecylamine/trioctylphosphine oxide ligands) in a hybrid heterostructure with poly $(9,9-$ di-n-octylfluorenyl-2,7-diyl) (PFO) conductive polymer. We further examined the application of that heterostructure to a white light-emitting structure by employing tris-(8hydroxyquinoline)aluminum $\left(\mathrm{Alq}_{3}\right)$ as a green light emitter. The collective emission of $\mathrm{PFO}, \mathrm{CdSe} \mathrm{QDs}$, and $\mathrm{Alq}_{3}$ results in a fairly white OLED with Commission Internationale del'Eclairage coordinates (CIE) of $(x, y)=(0.32,0.40)$ for a range of applied voltages between 5 and 10 volts. It is found that the blue and red parts are originated from the emission of PFO and CdSe QDs, respectively.

\section{Experimental}

2.1. Materials. Poly(2,3-dihydrothieno-1,4-dioxin)-poly(styrenesulfonate) $\left(1.3-1.7 \%\right.$ in water, conductivity: $10^{-3} \mathrm{~S} / \mathrm{cm}$, PEDOT:PSS), poly(9,9-di-n-octylfluorenyl-2,7-diyl) (PFO), CdSe nanocrystalline QDs (5 mg/mL; surface-stabilized with hexadecylamine/trioctylphosphine oxide ligands (TOPO)) $(6.5 \mathrm{~nm}$ particle size with emission at $640 \mathrm{~nm}$, FWHM < $40 \mathrm{~nm}$ ), and tris-(8-hydroxyquinoline) aluminum ( $\mathrm{Alq}_{3}$ ) were obtained from Aldrich (Scheme 1). TOPO ligands 


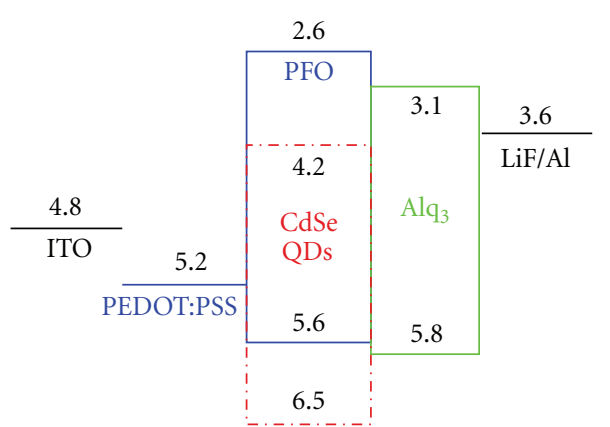

Scheme 2: Energy diagram of the proposed structure.

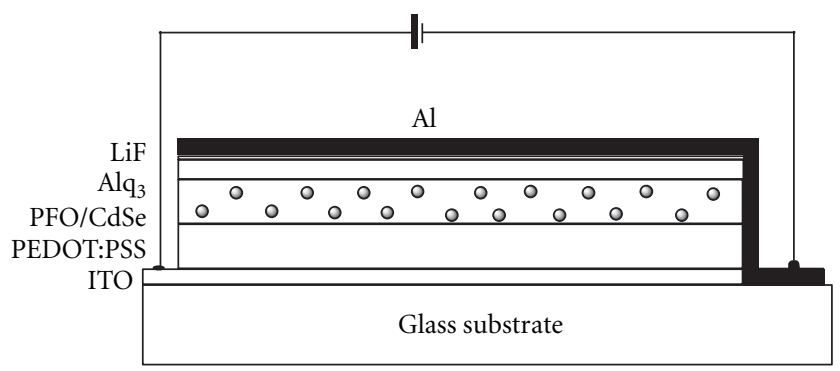

Scheme 3: Electroluminescence device in a cross-sectional configuration.

protect the QDs from chemical degradation, and their surface is electronically passivated. Furthermore, all the solvents, lithium fluoride (LiF), aluminium foil (99.999\%), and Indium Tin Oxide-coated glass slide (surface resistivity $8-12 \Omega /$ sq, ITO) for the OLED construction were also obtained from Aldrich. The other chemicals were of the best quality and used as received without any further purification.

2.2. Apparatus and Measurements. Absorption and photoluminescence (PL) spectra were collected with Analytik Jena s 600 UV-Vis spectrophotometer and PTI-QM1 luminescence photospectrometer, respectively. Laurell WS-400B6NPP-LITE spin processor was used in the preparation of PEDOT:PSS and PFO layers. The thickness of all the layers performed by spin coating was measured by either an Ambios XP-1 high-resolution surface profilometer or FESEM (LEO SUPRA 35VP) in cross-sectional modification. Thermal evaporation of $\mathrm{Alq}_{3}$ was performed in an NTE-3000 thermal evaporator whereas LiF and aluminum depositions were performed in a thermal evaporator plant attached in MBRAUN 200B glove box system. The thickness of all the layers performed by vacuum evaporation was measured by quartz crystal thickness monitor placed near the substrate in both of the vacuum evaporation systems. $J$ - $V$ curves of electroluminescent devices were obtained with a Keithley 2400 source meter. Electroluminescence (EL) spectra were collected with an Ocean Optic USB4000 spectrometer while brightness and C.I.E chromaticity colour measurements were obtained with a Konica Minolta Chroma Meter CS200.

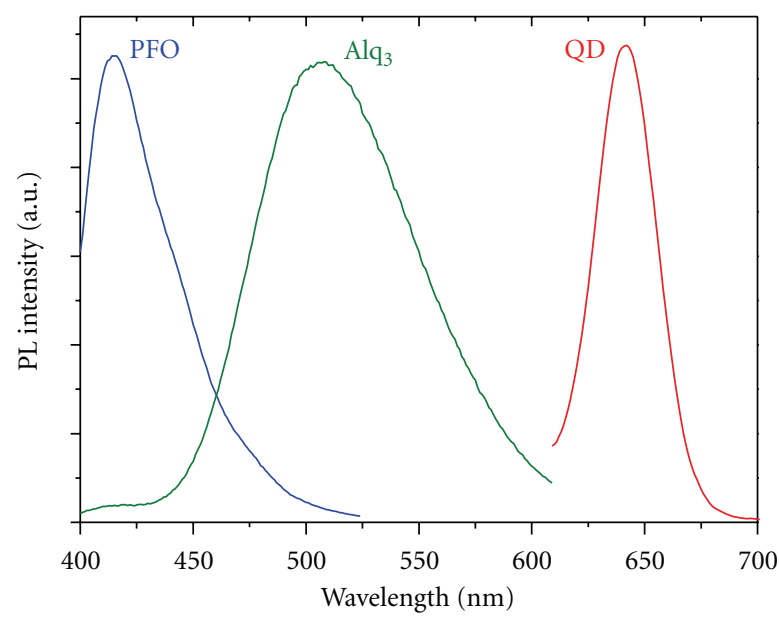

FIGURE 1: Photoluminescence spectra of PFO, $\mathrm{Alq}_{3}$, and CdSe QDS in toluene solution.

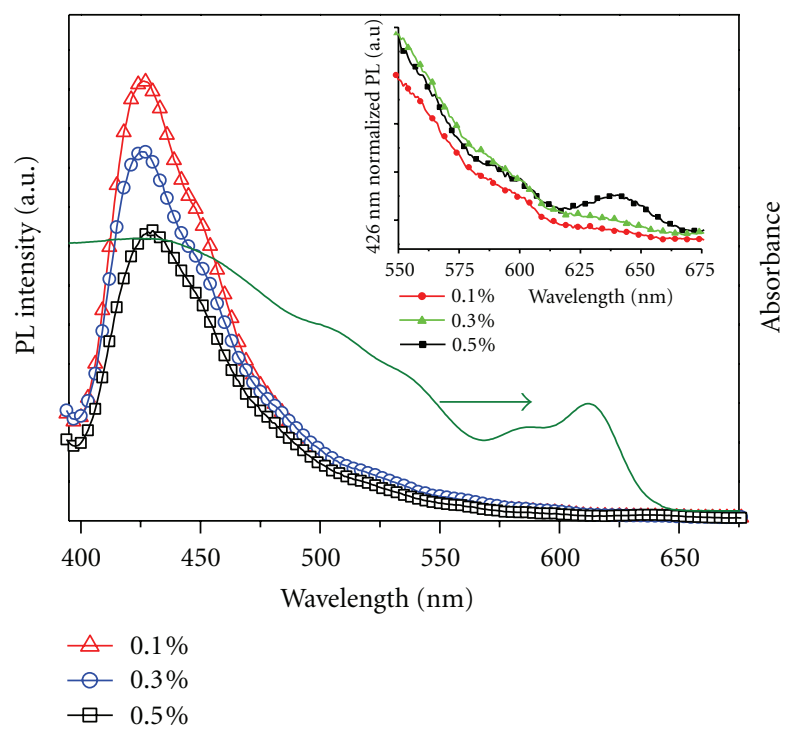

FIGURE 2: Photoluminescence spectra of PFO:QD composite films and absorbance of CdSe QDs in toluene solution. The magnified area of $550-675 \mathrm{~nm}$ for PL is presented as an inset. The excitation wavelength was $370 \mathrm{~nm}$.

2.3. Device Fabrication. OLEDs were fabricated in the standard configuration. Subsequent layers were deposited on Indium Tin Oxide (ITO) glasses. ITO glass substrates were carefully cleaned with detergent followed by treatment in ultrasonic bath using two different solvents (in isopropanol and subsequently in acetone). PEDOT:PSS conductive polymer was deposited by spin coating at $2500 \mathrm{rpm}$ using an aqueous solution of $1.3-1.7 \% \mathrm{w} / \mathrm{w}$ (film thickness $90 \mathrm{~nm}$ ). The films were thermally annealed for $30 \mathrm{~min}$ in an oven at $100^{\circ} \mathrm{C}$. On the top of the film subsequently a layer of PFO (thickness $55 \mathrm{~nm}$ ) was spin-coated at $2000 \mathrm{rpm}$ from a toluene solution. The concentration of $\mathrm{PFO}$ was $10 \mathrm{mg} / \mathrm{mL}$. Alternatively, layers of CdSe QDs/PFO heterostructures were deposited at the same speed in an average thickness of 70$120 \mathrm{~nm}$. The films were also annealed at $100^{\circ} \mathrm{C}$ for $30 \mathrm{~min}$. 


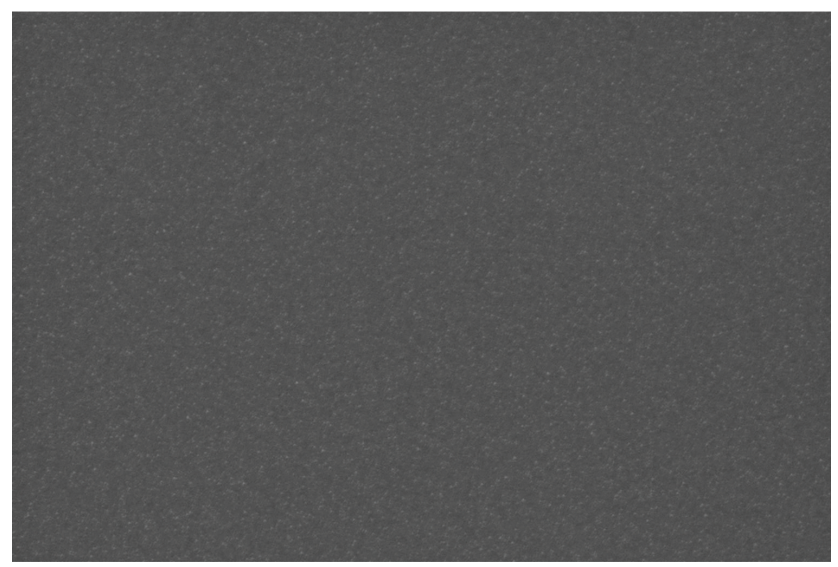

\begin{tabular}{lll} 
Mag $=10.00 \mathrm{kX}$ & EHT $=5.00 \mathrm{kV}$ & Date: 25 Sep 2008 \\
$1 \mu \mathrm{m}$ & WD $=7 \mathrm{~mm}$ & Time: $17: 44: 31$ \\
\hline & Signal A = InLens & Noise reduction = pixel Avg.
\end{tabular}

(a1)

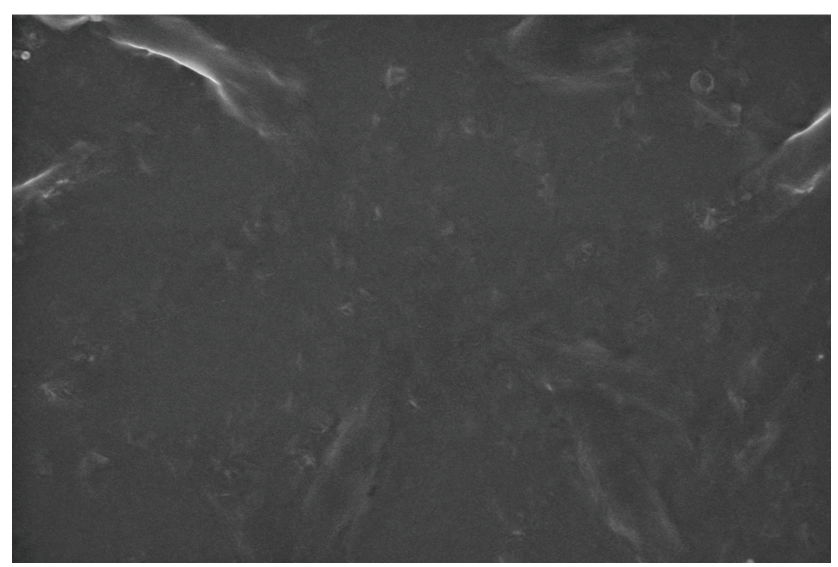

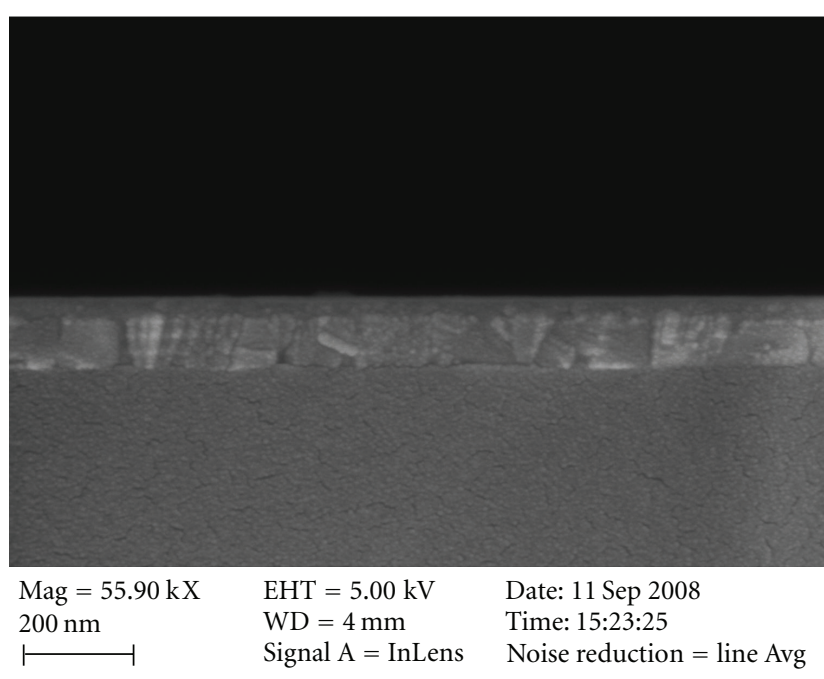

(a2)

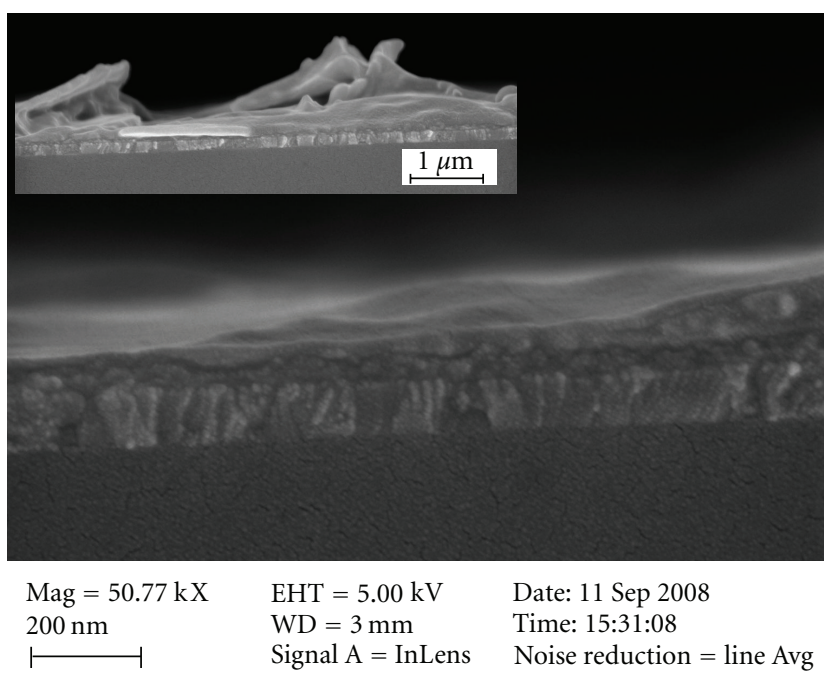

(b2)

(b1)

FIGURE 3: (a1) FE-SEM image of the surface and (a2) a cross-sectional image of the PFO film. (b1) FE-SEM image of the surface and (b2) a cross-sectional image of the PFO film with $0.3 \mathrm{~mL}$ of CdSe QDs. Lower magnification of (b2) is presented as an inset.

The PFO:CdSe structure was prepared by mixing $0.5 \mathrm{~mL}$ of PFO $(10 \mathrm{mg} / \mathrm{mL})$ with CdSe $(5 \mathrm{mg} / \mathrm{mL})$ in toluene under vigorous stirring. The quantity of CdSe was varied from 0 to $0.5 \mathrm{~mL}$. In the case of white light-emitting devices, tris-(8-hydroxyquinoline)aluminum salt ( $\left.\mathrm{Alq}_{3}\right)(15 \mathrm{~nm})$ was thermally evaporated in vacuum $\left(10^{-7}\right.$ mbar $)$ on the top of the composite layer of PFO:CdSe. The devices were completed by the successful thermal evaporation of $\operatorname{LiF}(1 \mathrm{~nm})$ and $\mathrm{Al}$ metal $(65 \mathrm{~nm})$ representing the negative electrode of the structure. The very thin layers of LiF were used to enhance electron injection [21] as it controls the energy mismatch between aluminum and $\mathrm{Alq}_{3}$ (Scheme 2). The cell (Scheme 3) was characterized under nitrogen atmosphere inside a glove box. The active area of the cells was $3 \times 5 \mathrm{~mm}^{2}$.

\section{Results and Discussion}

3.1. Photoluminescence Studies. The photoluminescence spectra of $\mathrm{PFO}, \mathrm{CdSe} \mathrm{QDs}$, and $\mathrm{Alq}_{3}$ in toluene are presented in Figure 1. It is already known that the creation of white light is possible by the simultaneous emission of the three materials (blue, red, and green). However, in OLED technology that involves inorganic semiconductors (e.g., QDs), two types of structures can appear: in the first type a thin layer of QDs is placed between an electron and a hole injection layer where the excitons are directly formed in the QDs' layer [22]. In the second type a blend of a polymer and QDs appears as a composite material serving as emissive trap for excitons that are generated in the polymer matrix by charge carrier recombination [23]. Usually, the 


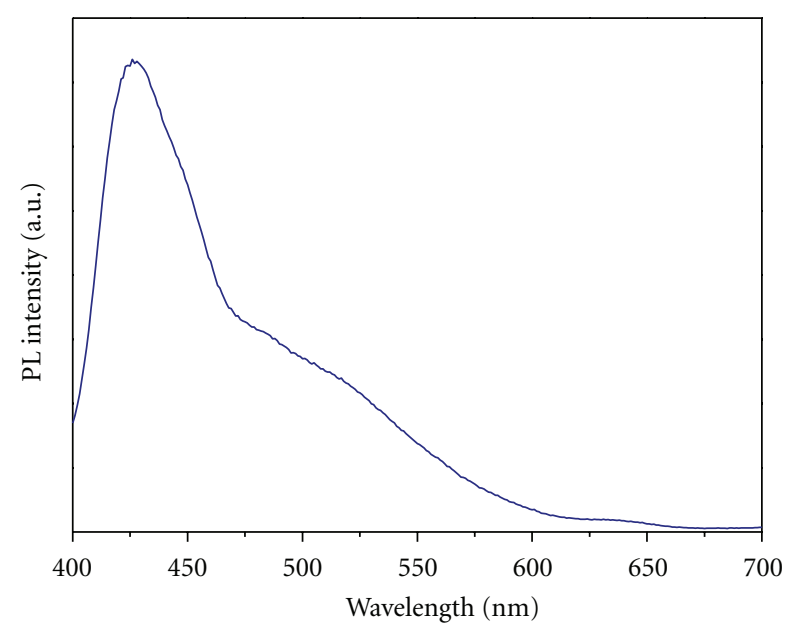

Figure 4: Photoluminescence spectrum of PFO/CdSe QDs/Alq composite film. The excitation wavelength was $370 \mathrm{~nm}$.

films consisting of only QDs are inhomogeneous thus we only examined the case of the PFO/CdSe QDs blend. In this case an optimum concentration of CdSe QDs in PFO polymer has to be identified for stable and highly emissive devices. We monitored the photoluminescence of this composite material with varied concentration of QDs in order to explore the optimum concentration of the inorganic particles in the polymer producing homogeneous films with intense emission and avoid phase segregation of QDs. The absorption of CdSe QDs in toluene solution and the emission spectra of PFO:QD composites in films are shown in Figure 2. It is clearly seen that there exists a spectral overlap between the emission of $\mathrm{PFO}$ and the absorption of CdSe QDs. Therefore, an energy transfer from PFO to CdSe QDs could happen when PFO is doped with CdSe QDs. The more the extent of spectral overlap the more efficient the energy transfer. To investigate the possible energy transfer in films, different mass ratios of QDs were mixed with always the same PFO quantity. A significant decrement in the emission intensity of PFO is observed with the increasing QD concentration in the composite. At the same time, the emission intensity of the QDs increases (inset of Figure 2), consistent with the expected energy transfer, but also possibly due to direct excitation. However, it should be noted that a large emission peak at $420 \mathrm{~nm}$ from PFO is also observed in PFO/CdSe QDs composite thin film. This demonstrates that the energy transfer from PFO to the CdSe QDs is incomplete. Besides the content of $0.3 \mathrm{wt} \%$ of QDs in the sol was the optimum for the homogeneity of the films as it is shown in Figure 3. The presence of high load of QDs in the PFO film causes a rough surface because of phase segregation, with detrimental effect to the stability of the electroluminescent devices [24]. From the images presented in Figure 3, it is obvious that the presence of QDs in the blend causes a rough film surface with small islands of inorganic material which is more intense in the case of higher quantities of the QDs in the films. In general, the quantity of $0.3 \mathrm{wt} \%$ of QDs is the optimum for overcoming the stability problems of our devices.
Photoluminescence spectrum of the composite film containing the blend of PFO/CdSe QDs and $\mathrm{Alq}_{3}$ as a separate layer on the top is presented in Figure 4. The wavelength of excitation was $370 \mathrm{~nm}$. The emission of PFO appears as an intense peak at $427 \mathrm{~nm}$, and $\mathrm{Alq}_{3}$ accompanies it with a shoulder located at $470-580 \mathrm{~nm}$. The QDs emission is observed as a weak peak at around $640 \mathrm{~nm}$.

3.2. Electroluminescence Studies. We first prepared a device with only PFO in a sandwich configuration between an ITO/PEDOT:PSS anode and an LiF/Al cathode. The corresponding EL spectra are presented in Figure 5(a). They have a broad structure, and, for $12 \mathrm{~V}$ of applied voltage, the EL maxima are located at 437, 463, 500, and $530 \mathrm{~nm}$. The blue colour $[(x, y)=(0.18,0.18)]$ is originated from the PFO emission. PFO photoluminescence (structured blue emission, $425 \mathrm{~nm}$ ) and electroluminescence spectra (unstructured bluish-green emission, $500 \mathrm{~nm}$ ) are noticed to be different. This spectral feature of fluorenyl derivatives is referred in the literature as keto-emission [25]. The turn-on voltage for this device was estimated at 6 volts.

The EL spectra of the device that contains composite film of $\mathrm{PFO} / \mathrm{CdSe} \mathrm{QDs}$ as emissive layer in the same sandwich configuration of ITO/PEDOT:PSS anode and LiF/Al cathode are presented in Figure 5(b). The detected EL maxima are identical with the former device. However the colour of the emitted light was bluish-red $[(x, y)=(0.24-0.3,0.11-0.2)]$. When compared to Figure 5(a) the intensity of EL observed at $500 \mathrm{~nm}$ is significantly decreased. The presence of QD may have caused a reduction in the keto-defect sites of polymer and prevent the excitons formed on PFO hopping to other chains [26]. The EL intensity decrease at around $500 \mathrm{~nm}$ is not the only difference observed with the incorporation of QDs. It also causes a broadening in the EL wavelength, that is, extension of the EL spectrum's red region and tail from $650 \mathrm{~nm}$ (Figure 5(a)) to $750 \mathrm{~nm}$ (Figure 5(b)). Therefore, we think that some of the injected holes and electrons have formed excitons on the CdSe cores that result in the EL from CdSe QDs. When the quantity of the QDs was increased a gradual enhancement in EL intensity is monitored and the colour gradually turned to red. This result points out that CdSe QDs have become direct recombination sites for the charges. However, the devices were unstable, most probably because of the high QD concentration. The turn-on voltage for the device was slightly decreased compared to the previous structure with only PFO, and it was found to be 5 volts.

Finally, we examined the device architecture described in Scheme 3 which also contains an electron transporting/emissive material $\mathrm{Alq}_{3}$, a green light emitter, as a separate layer on the top of the PFO/CdSe QDs film. The energy diagram of all materials is shown in Scheme 2. The EL maximum of this device is located at $530 \mathrm{~nm}$ (Figure 5(d)). The emission is white-coloured with the CIE coordinates of $(x, y)=(0.32,0.40)$. The EL behaviour of this device basically depends on the presence of $\mathrm{Alq}_{3}$. It is also obvious that the emission of $\mathrm{Alq}_{3}$ is electrically excited. Indeed, from data presented in Figure 5(c), $\mathrm{Alq}_{3}$ emission by the electric bias of ITO/PEDOT:PSS/PFO/Alq $/ 2 / \mathrm{LiF} / \mathrm{Al}$ structure 


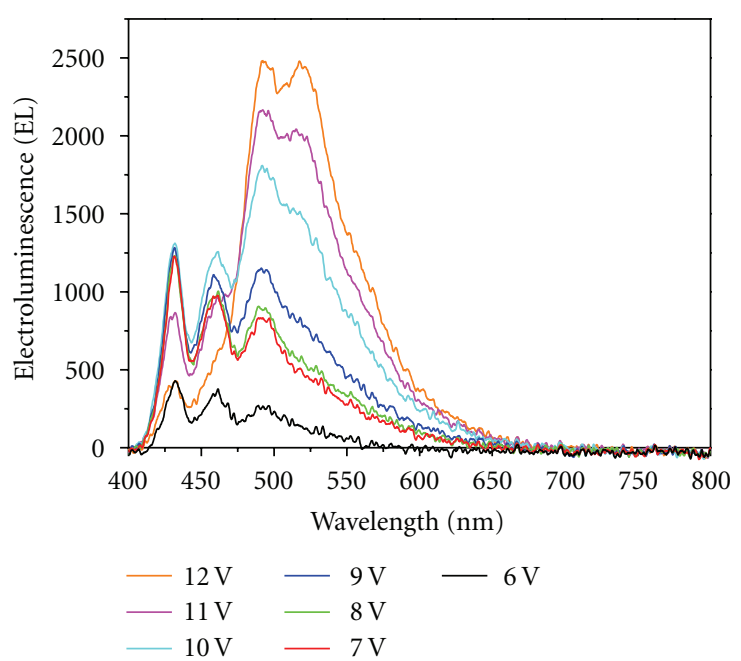

(a)

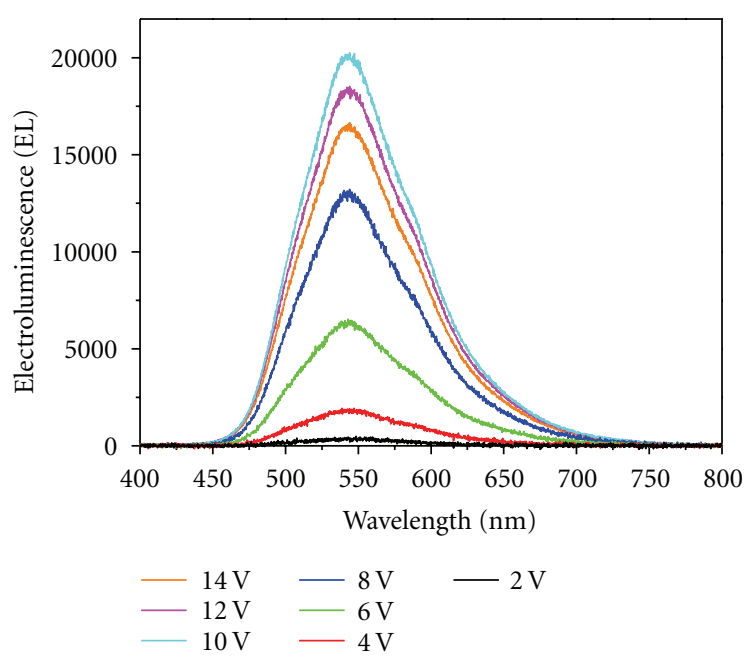

(c)

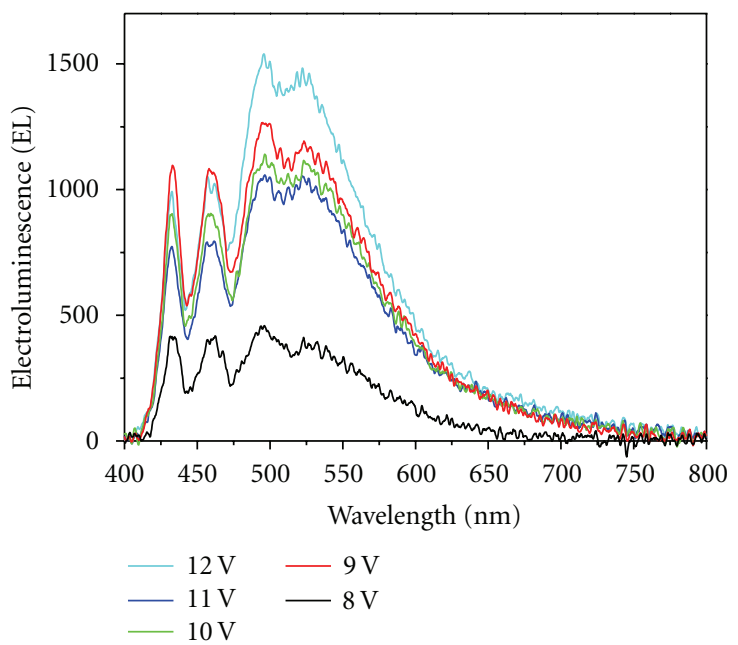

(b)

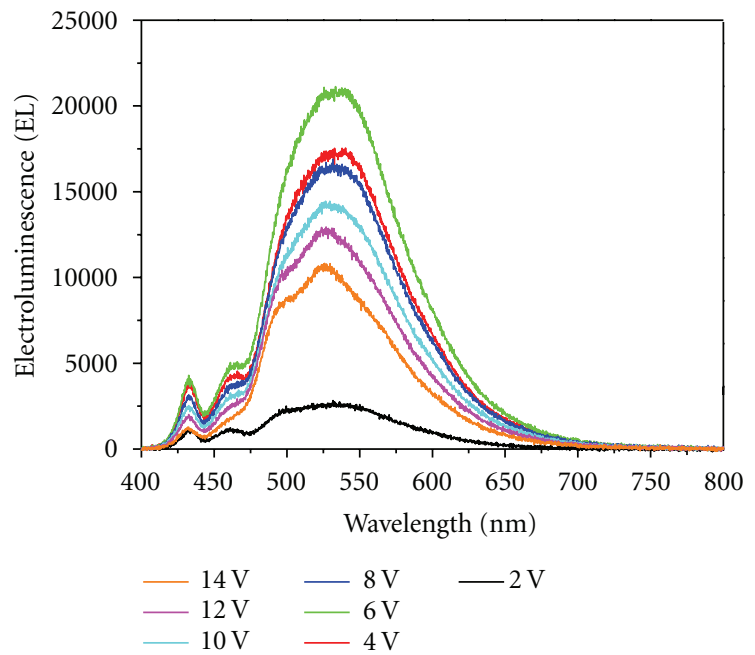

(d)

FIGURE 5: EL spectra of (a) ITO/PEDOT:PSS/PFO/LiF/Al, (b) ITO/PEDOT:PSS/PFO (CdSe QDs)/LiF/Al, (c) ITO/PEDOT:PSS/PFO/Alq 3 / $\mathrm{LiF} / \mathrm{Al}$ cell, and (d) ITO/PEDOT:PSS/PFO(CdSe QDs)/Alq $3 / \mathrm{LiF} / \mathrm{Al}$ cells.

without the presence of any CdSe QDs is located at $543 \mathrm{~nm}$ without any change to shape and spectra maxima by voltage increase. The emission is green-coloured with CIE coordinates $(x, y)=(0.35,0.54)$. Combining the data presented in Figures 5(c) and 5(d) we may conclude that the presence of CdSe quantum dots results in the white colour of the electrically pumped devices. The EL maximum is blue-shifted as a result of keto-emission quenching of PFO in the presence of QDs and CIE coordinates also moved to the white region. In order to understand the origin of white light emission in our devices it is needed to have an insight to the electrical excitation process. Two independent excitation mechanisms could happen: (a) energy transfer from the fluorescent polymer, PFO (host) to the QDs and $\mathrm{Alq}_{3}$ (guests) or (b) charge trapping at the emitter sites. From data presented in Figures 4 and 5(d) a significant deviation between EL and PL spectra is observed which can be assigned to a trapping mechanism in EL spectrum than to an energy transfer. A simultaneous excitation of blue emitting polymer ( $\mathrm{PFO}$ ) and green emitting small molecule $\left(\mathrm{Alq}_{3}\right)$ via direct charge trapping may occur. The turn-on voltage (Figure 6(a)) for this device is compared to that of the device with PFO/QDs blend, and it was found to be lower ( 4.5 volts). The luminance of the device is found to be $270 \mathrm{~cd} / \mathrm{m}^{2}$ with a current and power efficiency at 8.5 volts of $0.8 \mathrm{~cd} / \mathrm{m}^{2}$ and $0.27 \mathrm{~lm} / \mathrm{W}$, respectively.

The $x-y$ CIE coordinates of the four devices are presented in Figure 7. The driving voltage was varied from 5 to 10 volts for each of them. As it can be seen from the results the white light emission is quite stable for a variety of applied voltages.

\section{Conclusions}

A hybrid organic light-emitting diode based on CdSe quantum size particles as red light emitters in $\operatorname{poly}(9,9-\mathrm{di}-$ $n$-octylfluorenyl-2,7-diyl) as a host polymer was fabricated. 


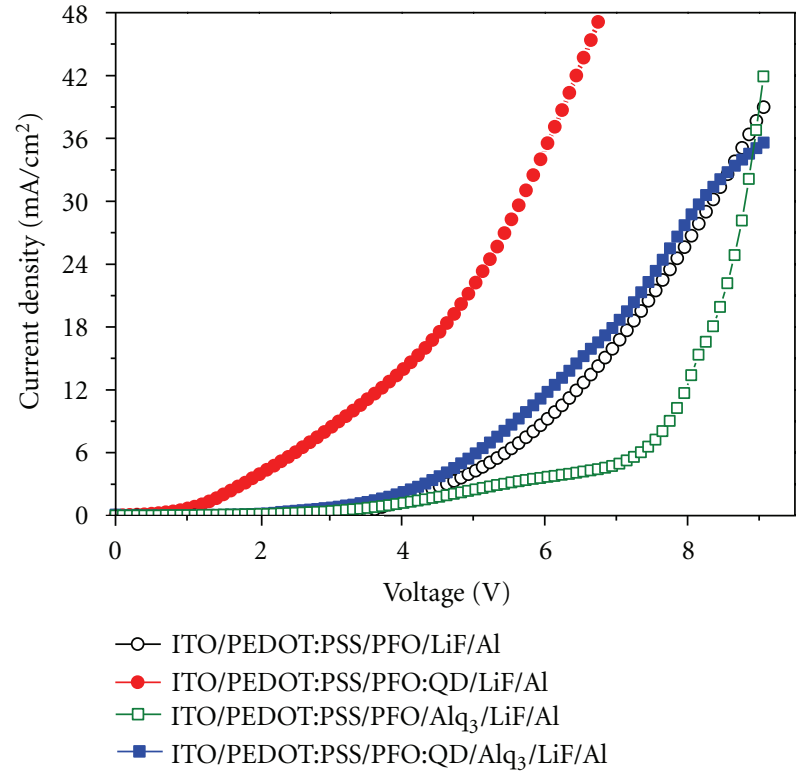

(a)

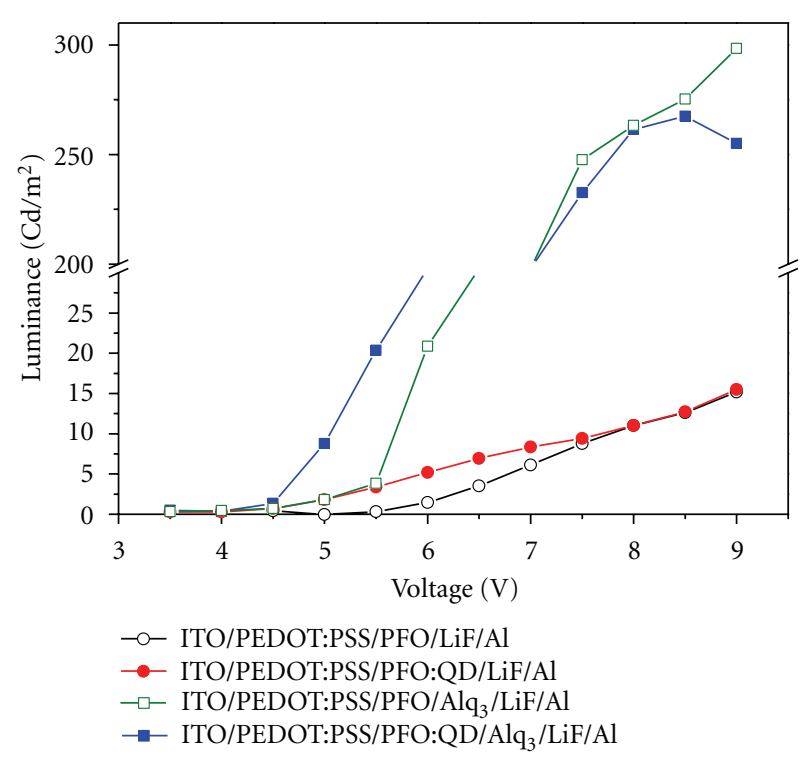

(b)

Figure 6: (a) Current density versus applied voltage and (b) luminance versus voltage of the four devices.

The optimum concentration of CdSe QDs was examined in order to fabricate a stable device overcoming the phase segregation problems in the CdSe quantum dots/polymer blend. However, we suggest a noncompletely uniform dispersion of CdSe QDs with particle small islands formation in the polymer layer. The coexistence of a thin layer of electron transporting material $\mathrm{Alq}_{3}$ in the OLED device allowed a fairly pure white light emission with CIE coordinates $(0.32,0.40)$. Further experiments on the improvement of EL performance are still in progress.

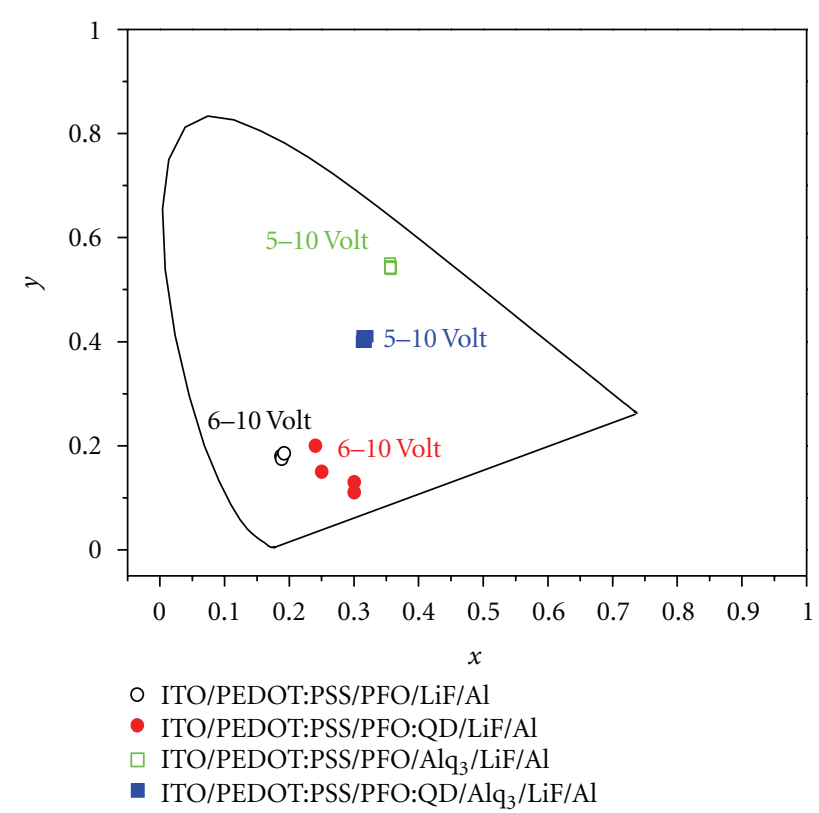

FIGURE 7: $x-y$ CIE coordinates of the four devices in varied driving voltage.

\section{Acknowledgments}

The authors acknowledge financial supports of Visiting Scientists Fellowship Program of the Scientific and Technological Research Council of Turkey (TUBITAK) and research project funds of Ege University.

\section{References}

[1] D. G. Fink and H. W. Beaty, Standard Handbook for Electrical Engineers, McGraw-Hill, New York, NY, USA, 11th edition, 1978.

[2] C. W. Tang and S. A. Vanslyke, "Organic electroluminescent diodes," Applied Physics Letters, vol. 51, no. 12, pp. 913-915, 1987.

[3] J. H. Burroughes, D. D. C. Bradley, A. R. Brown et al., "Lightemitting diodes based on conjugated polymers," Nature, vol. 347, no. 6293, pp. 539-541, 1990.

[4] S. Logothetidis, "Flexible organic electronic devices: Materials, process and applications," Materials Science and Engineering B, vol. 152, no. 1-3, pp. 96-104, 2008.

[5] H. Wu, G. Zhou, J. Zou et al., "Efficient polymer white-lightemitting devices for solid-state lighting," Advanced Materials, vol. 21, no. 41, pp. 4181-4184, 2009.

[6] Y. J. Pu, M. Higashidate, K. I. Nakayama, and J. Kido, "Solution-processable organic fluorescent dyes for multicolor emission in organic light emitting diodes," Journal of Materials Chemistry, vol. 18, no. 35, pp. 4183-4188, 2008.

[7] S. Y. Ryu, J. T. Kim, J. H. Noh et al., "Polymeric tandem organic light-emitting diodes using a self-organized interfacial layer," Applied Physics Letters, vol. 92, no. 10, Article ID 103301, 2008.

[8] L. Yan, J. Y. Zhang, Y. Cui, and Y. Qiao, "Voltage-dependent electroluminescence from colloidal CdSeZnS quantum dots," Applied Physics Letters, vol. 91, no. 24, Article ID 243114, 2007. 
[9] I. Ugarte, W. Cambarau, C. Waldauf, F. L. Arbeloa, and R. Pacios, "Precisely voltage tunable polymeric light emitting diodes by controlling polymer chemical oxidation and adding inorganic semiconducting nanoparticles. From blue to red stopping at white in the same device," Organic Electronics, vol. 10, no. 8, pp. 1606-1609, 2009.

[10] C. W. Lee, C. H. Chou, J. H. Huang, C. S. Hsu, and T. P. Nguyen, "Investigations of organic light emitting diodes with $\mathrm{CdSe}(\mathrm{ZnS})$ quantum dots," Materials Science and Engineering $B$, vol. 147, no. 2-3, pp. 307-311, 2008.

[11] G. Tu, C. Mei, Q. Zhou et al., "Highly efficient pure-whitelight-emitting diodes from a single polymer: polyfluorene with naphthalimide moieties," Advanced Functional Materials, vol. 16, no. 1, pp. 101-106, 2006.

[12] Q. J. Sun, B. H. Fan, Z. A. Tan, C. H. Yang, Y. F. Li, and Y. Yang, "White light from polymer light-emitting diodes: utilization of fluorenone defects and exciplex," Applied Physics Letters, vol. 88, no. 16, Article ID 163510, 2006.

[13] J. H. Jou, W. B. Wang, C. C. Chen et al., "High-efficiency phosphorescent and fluorescent pure-white organic lightemitting diodes by incorporating small nano-dot in nonemissive layer," IEICE Transactions on Electronics, vol. E91, no. 10, pp. 1532-1535, 2008.

[14] A. L. Rogach, N. Gaponik, J. M. Lupton et al., "Lightemitting diodes with semiconductor nanocrystals," Angewandte Chemie. International Edition, vol. 47, no. 35, pp. 6538-6549, 2008.

[15] V. L. Colvin, M. C. Schlamp, and A. P. Alivisatos, "Lightemitting diodes made from cadmium selenide nanocrystals and a semiconducting polymer," Nature, vol. 370, no. 6488, pp. 354-357, 1994.

[16] P. O. Anikeeva, J. E. Halpert, M. G. Bawendi, and V. Bulović, "Electroluminescence from a mixed red-green-blue colloidal quantum dot monolayer," Nano Letters, vol. 7, no. 8, pp. 21962200, 2007.

[17] F. Teng, A. Tang, B. Feng, and Z. Lou, "The optical properties of the blends of CdSe nanocrystals and poly $(\mathrm{N}$ vinylcarbazole)," Applied Surface Science, vol. 254, no. 20, pp. 6341-6345, 2008.

[18] Z. S. Guo, L. Zhao, J. Pei et al., "CdSe/ZnS Nanoparticle composites with amine-functionalized polyfluorene derivatives for polymeric light-emitting diodes: synthesis, photophysical properties, and the electroluminescent performance," Macromolecules, vol. 43, no. 4, pp. 1860-1866, 2010.

[19] I. H. Campbell and B. K. Crone, "Efficient, visible organic light-emitting diodes utilizing a single polymer layer doped with quantum dots," Applied Physics Letters, vol. 92, no. 4, Article ID 043303, 2008.

[20] S. Nizamoglu and H. V. Demir, "Excitation resolved color conversion of CdSe/ZnS core/shell quantum dot solids for hybrid white light emitting diodes," Journal of Applied Physics, vol. 105, no. 8, Article ID 083112, 2009.

[21] S. B. Shin, S. C. Gong, J. K. Jang et al., "Properties of polymer light-emitting diodes coated on surface-treated ITO/glass substrates," Journal of Applied Polymer Science, vol. 110, no. 6, pp. 3678-3682, 2008.

[22] R. A. M. Hikmet, P. T. K. Chin, D. V. Talapin, and H. Weller, "Polarized-light-emitting quantum-rod diodes," Advanced Materials, vol. 17, no. 11, pp. 1436-1439, 2005.

[23] L. Bakueva, S. Musikhin, M. A. Hines et al., "Sizetunable infrared (1000-1600 nm) electroluminescence from $\mathrm{PbS}$ quantum-dot nanocrystals in a semiconducting polymer," Applied Physics Letters, vol. 82, no. 17, pp. 2895-2897, 2003.
[24] M. Zorn, W. Ki Bae, J. Kwak et al., "Quantum dot-block copolymer hybrids with improved properties and their application to quantum dot light-emitting devices," ACS Nano, vol. 3, no. 5, pp. 1063-1068, 2009.

[25] S. I. Hintschich, C. Rothe, S. Sinha, A. P. Monkman, P. Scandiucci de Freitas, and U. Scherf, "Population and decay of keto states in conjugated polymers," Journal of Chemical Physics, vol. 119, no. 22, pp. 12017-12022, 2003.

[26] A. P. Monkman, H. D. Burrows, L. J. Hartwell, L. E. Horsburgh, I. Hamblett, and S. Navaratnam, "Triplet energies of $\pi$-conjugated polymers," Physical Review Letters, vol. 86, no. 7, pp. 1358-1361, 2001. 

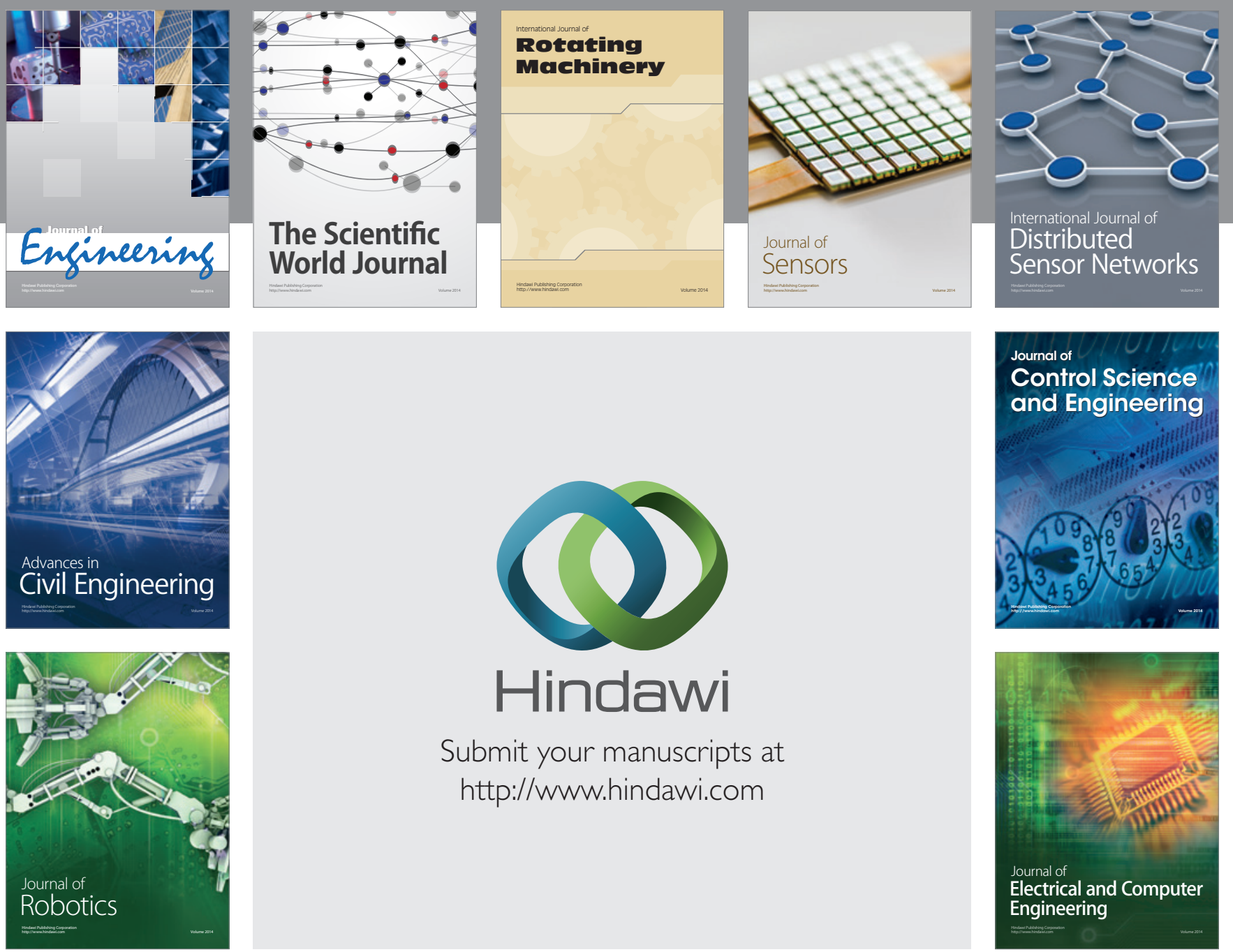

Submit your manuscripts at

http://www.hindawi.com
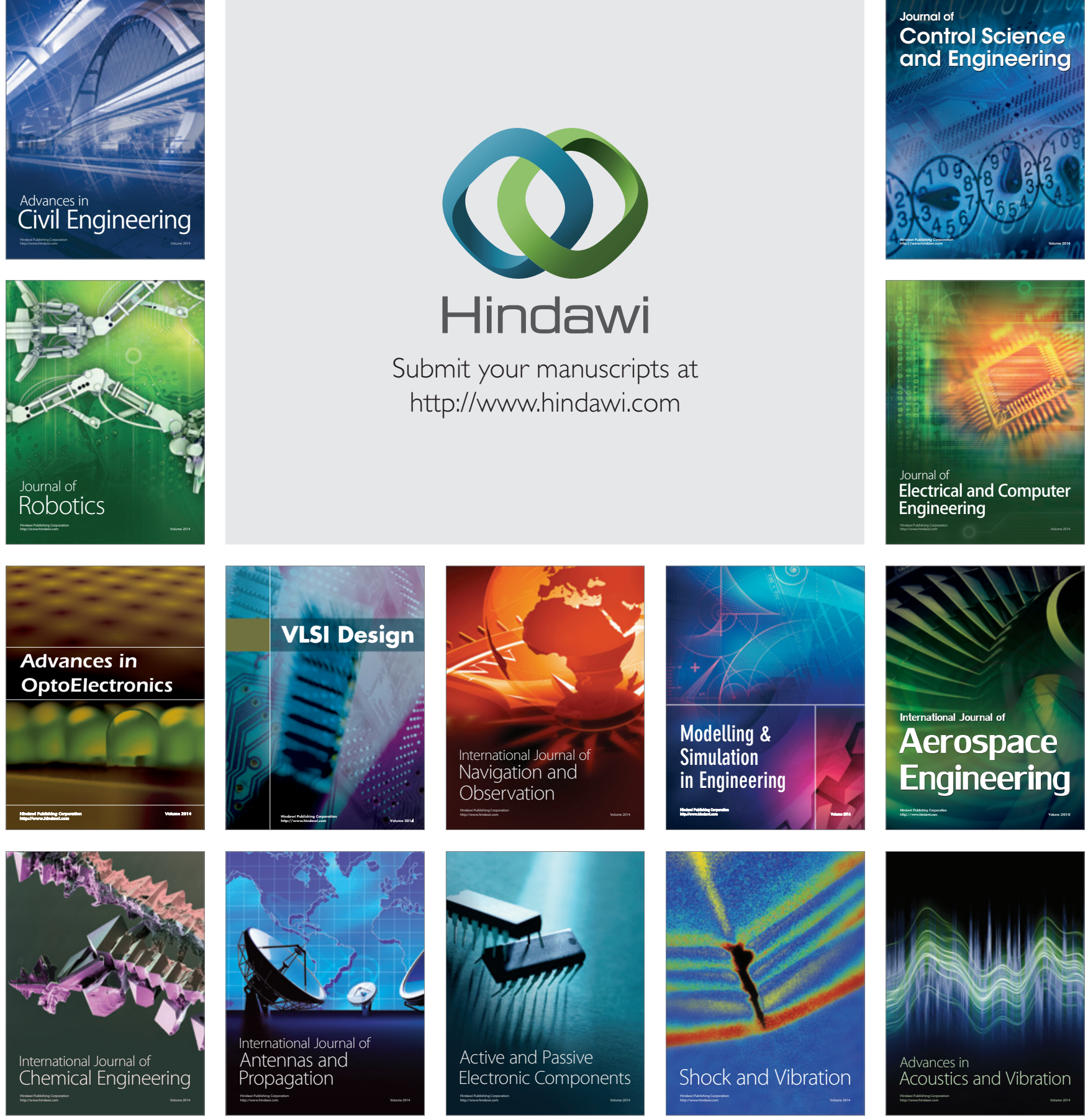